\title{
Dinâmica e Espacialidade das Saunas de Boys na Cidade do Rio de Janeiro
}

\author{
Dynamics and geographical distribution of saunas that host male prostitutes \\ ('boys') in the city of Rio de Janeiro
}

\author{
Miguel Angelo Ribeiro \\ Universidade do Estado do Rio de Janeiro \\ mamikisi@gmail.com \\ Rafael da Silva Oliveira \\ Universidade Federal de Roraima \\ rafasolufrr@gmail.com \\ Gessé da Silva Maia \\ Universidade do Estado do Rio de Janeiro \\ g-silva-maia@bol.com.br
}

"O bom cliente é o que paga bem, não importa nada" (Boy, 2005).

\section{Resumo}

O artigo analisa a dinâmica e a espacialidade das saunas masculinas de relações homocomerciais na cidade do Rio de Janeiro, fruto do resultado de pesquisas entre os anos de 2005 e 2011. Tais, configuram micro territórios, nos quais regras, normas de conduta, códigos e práticas são ditados por seus proprietários e que terão que ser previamente respeitados pelos boys (rapazes de programa) e clientes que as frequentam A metodologia da pesquisa constituiu-se de trabalho de campo, conversas informais com clientes, entrevistas com boys (garotos de programa) e proprietários, levantamento fotográfico, além da utilização de sites específicos, coleta de panfletos, dentre outros. $\mathrm{Na}$ primeira parte discute-se o conceito de território à luz da prostituição; na segunda, analisa a espacialidade das saunas na cidade do Rio de Janeiro e sua dinâmica.

Palavras - chave: Prostituição masculina; saunas e private clubs; relações homocomerciais; Rio de Janeiro

\begin{abstract}
This article analyzes the dynamics and geographical distribution of male saunas run for male homosexual prostitution in the city of Rio de Janeiro, and is the result of a research undertaken between 2005 and 2011. These locations are 'micro-territories', in which the rules, norms of behavior, codes and practices are dictated by the owners of the premises and obeyed by the 'boys' (male prostitutes) and the clients that frequent them. The research methodology comprised field research, informal interviews with clients, 'boys' and sauna owners, a photographic survey, as well as a research undertaken on specialized websites and flyers collected in the streets, among other sources. The first part of this article discussed the concept of territory, with regards to prostitution; the second analyzes the geographical distribution of the saunas in the city of Rio de Janeiro, and its dynamics.
\end{abstract}

Keywords: Male prostitution; saunas and private clubs; homosexual prostitution; Rio de Janeiro 


\section{Considerações Preliminares}

A prostituição masculina na cidade do Rio de Janeiro, em um largo período de tempo, mais especificadamente do final do século XIX até o final dos anos 1970, ficou exclusiva aos logradouros (MATTOS, 2002). Atualmente, este tipo de prostituição encontra-se em processo de desaparecimento na Área Central, local em que havia territórios configurados, como apontaram Ribeiro e Mattos (1995), sendo encontrado em recintos fechados, como, por exemplo, nas saunas e private clubs de boys (saunas com relações homocomerciais), objeto de nosso estudo; mas também oferecido em sites especializados através de serviços de massagem e acompanhantes. Seu crescimento pode ser explicado pelo aumento da violência ocorrida nos espaços públicos da cidade, contribuindo, entre outros fatores, para o desaparecimento daquele tipo de prostituição. Sendo assim, a partir do início dos anos 1980, é gestada a prostituição fechada masculina no bairro de Copacabana. Vale ressaltar que existem duas modalidades de saunas masculinas voltadas para o público gay no Brasil, em importantes metrópoles e algumas cidades médias, a saber: as saunas de 'pegação'1 e aquelas com a presença de boys.

Em se tratando do Rio de Janeiro, as saunas de 'pegação' distribuem-se em maior número pelo espaço e disseminam-se pelos bairros do Leblon, Ipanema, Copacabana, Flamengo, Vila Isabel, dentre outros, mas com finalidade distinta do segmento abordado nesta pesquisa, existentes desde os anos 1970.

Neste contexto, podemos afirmar que a prostituição masculina fechada, exemplo das saunas e private clubs, já existe a mais de 30 anos, recebendo público não somente do Rio de Janeiro, mas também de outros Estados brasileiros e do exterior, público este, direcionado e exclusivamente gay.

Esses espaços fechados configuram micro territórios, nos quais: regras, normas de conduta, códigos e práticas são ditados por seus proprietários e que devem ser previamente respeitados pelos boys (rapazes de programa) e clientes que as frequentam, apresentando uma dinâmica extremamente singular (MAIA, 2007). Outro ponto relevante a ser discutido nesta pesquisa diz respeito a sua espacialidade.

Posto isto, o objetivo deste artigo, pioneiro nos estudos geográficos, é analisar a dinâmica e espacialidade das saunas masculinas de boys na cidade do Rio de Janeiro, fruto do resultado de pesquisas entre os anos de 2005 e 2011.

Para dar conta do objetivo proposto, cumpre mencionar a metodologia de pesquisa que constituiu o trabalho de campo: conversas informais com clientes, entrevistas com boys e proprietários, levantamento fotográfico, além do acesso a sites específicos, coleta de materiais de propaganda, entre outros procedimentos de investigação.

Desta forma, um trabalho geográfico que propõe estudar as relações sociais dos prostitutos (boys) no Rio de Janeiro não poderia prescindir de um conceito tão caro à Geografia - o de território. Sendo assim, o território e suas territorialidades relativas à prostituição e, especificamente, à masculina (boys) nas saunas, será um dos pilares de sustentação dos estudos relacionados a presente pesquisa. Diante do exposto, o artigo encontra-se estruturado em duas etapas. Na primeira, discutiremos o conceito de território à luz da prostituição; na segunda, procuraremos analisar a espacialidade das saunas na urbe carioca, a dinâmica das relações cliente-boy-cliente, o perfil dos boys, enfatizando pormenorizadamente a estrutura e mecanismos internos de uma das mais importantes saunas gay com presença de boys do país, o Club 117, localizado no bairro da Glória.

\section{Território e Prostituição Masculina: Uma Análise Teórico Conceitual}

A questão do território deve, necessariamente, ser abordada quando nos propomos a aprofundar o tema da prostituição nas saunas na cidade do Rio de Janeiro, pois entendemos que prostituição e território estão intimamente atrelados. Partimos então do conceito de território, entendido aqui como um espaço constituído a partir de relações de poder (RIBEIRO \& MATTOS, 1995; SOUZA, 1995).

Quando falamos em território, o conceito nos remete à ideia de mediação entre as relações humanas. A Geografia, enquanto ciência social mais ligada ao estudo desse conceito, passa a ser responsável pela articulação entre o território $\mathrm{e}$ as duas bases que o delimitam: o espaço e o poder.

Os limites territoriais impostos pela prostituição se caracterizam de distintas formas nos espaços urbanos das grandes cidades. No Rio de Janeiro, encontraremos diferentes territorialidades nos bairros da cidade. Cada indivíduo ou grupo de pessoas estabelece sua forma de demarcação, acesso e controle e seu território apropriado (SACK, 1986). A manutenção desse território depende diretamente da capacidade desse indivíduo ou grupo de pessoas exercer sua influência, impondo suas normas e condutas.

Devemos, contudo, lembrar que esse território possui delimitação simbólica, em que os limites são impostos, em alguns casos, pelo uso de violência como forma de legitimar sua posse. Para Campos (2000, p.28): 
(...) a identificação simbólica refere-se aos diferentes significados e valores que $o$ espaço assume para os diversos grupos sociais na busca da identificação; esta relação simbólica está muito diretamente associada às representações sociais. Essas representações são formadoras de uma trama complexa de diferentes significações que vão influenciar, motivar e mesmo justificar atitudes de resistência, defesa, animosidade dos grupos sociais em relação ao meio onde se encontram, do mesmo modo, as representações, construídas social e espacialmente, podem promover distinções de atratibilidade.

O território da prostituição possui uma especificidade bastante marcante, que consiste no fato de haver uma separação territorial nítida dos diferentes segmentos: prostitutas, michês (rapazes de programa) e travestis. As observações de campo deixaram evidente que cada grupo delimita seu próprio território. Desta maneira, não encontramos segmentos de travestis dividindo o mesmo espaço com prostitutas ou boys. Esta delimitação pode ser tênue, imperceptível ao olhar comum, mas a territorialidade se apresenta nitidamente para o olhar do geógrafo. Um exemplo elucidativo dessa territorialidade pode ser observado na Avenida Atlântica, em Copacabana, onde uma quadra, uma rua ou alguns metros do mesmo logradouro ou quadra podem significar o limite dos diferentes grupos de profissionais do sexo (RIBEIRO, 1997).

Assim, a materialização entre os grupos de prostituição é um produto da "instrumentalidade do espaço-poder-saber e forma a base para espacializar e temporalizar o funcionamento do poder" (RAFESTIN, 1993, p.159), enquanto que a territorialidade, para Soja (1993, p.183), teria como função "segregar e compartimentalizar a interação humana, controlando a presença/ ausência e a inclusão/ exclusão de outros grupos".

A territorialidade dos diferentes profissionais do sexo é definida não apenas pela iniciativa desses agentes, mas também por outros fatores que vão influenciar de forma decisiva na construção/ desconstrução desse território. Dentre eles, quatro fatores exercem maior influência para demarcar as áreas de atuação dos profissionais do sexo: intervenções frequentes por parte do Poder Público (polícia); dificuldade de acesso para os clientes (áreas periféricas); baixo poder aquisitivo dos possíveis clientes e rejeição por parte dos moradores locais e áreas muito degradadas.
Devemos salientar, contudo, que o território da prostituição, sobretudo a de garotos de programa (boys, michês), não se restringe aos espaços públicos. As saunas, objeto de nosso estudo, são espaços fechados com normas distintas daquelas toleradas nos espaços públicos ou abertos, onde a prostituição e, especialmente a masculina, adquire territorialidades distintas daquelas localizadas em recintos abertos. O território, nesses ambientes, tem um controle espacial mais intenso, em decorrência das regras e normatizações impostas pelos proprietários dos estabelecimentos, e não pelos profissionais do sexo, tendo os mesmos que seguir uma série de normas e condutas, definindo uma territorialidade específica, em um micro espaço que adquire relações de poder hierarquizadas.

Cumpre mencionar a dimensão identitária do território. Ela consiste no laço afetivo que o indivíduo cria com seu entorno. Isto posto, não apenas o poder exerce influência e identifica a territorialidade, mas também a identidade contribui para manifestação da territorialidade, a partir de laços afetivos criados entre o indivíduo e o lugar, o qual Tuan (1980) caracterizou como topofilia, que seria a ligação entre a pessoa e o lugar onde ela vive. O espaço, assim caracterizado, é capaz de criar uma relação afetiva entre o indivíduo e o ambiente físico, que pode ser transferida para a prostituição masculina e, em nosso caso específico, para os boys que frequentam as saunas de programa masculino.

Neste contexto, nosso próximo passo se destina à análise empírica, na qual abordaremos a distribuição espacial do interior das saunas que trabalham com a prostituição masculina na cidade do Rio de Janeiro e, por fim, o perfil dos boys.

\section{A Espacialidade e a Dinâmica das Saunas na Cidade do Río de J aneiro}

Antes de analisarmos a espacialidade das saunas masculinas, seria oportuno apresentar a metodologia da pesquisa de campo, realizada em visitas periódicas entre os anos de 2005 e 2011, aos ambientes fechados em diferentes bairros da cidade do Rio de Janeiro. O trabalho de campo foi realizado em distintas áreas, consequentemente com mudanças no conteúdo social, pois estes fixos, também conhecidos como 'casas de banho', apresentam entre si semelhanças e diferenças. As diferenças não se restringem apenas à localização, mas principalmente a uma série de fatores internos e externos ao próprio estabelecimento. Elas estão distribuídas por bairros da Zona Sul, da Área Central e entorno e no subúrbio. Normalmente, a localização das 
mesmas e o poder aquisitivo dos clientes determinam o custo e os serviços que cada estabelecimento oferecerá aos seus frequentadores.

Uma primeira grande diferença diz respeito ao preço do ingresso em relação à localização. Para acessar as saunas (todas as saunas, sem exceção, cobram um valor dos seus clientes e boys pela entrada), o preço estabelecido oscila muito de um bairro para outro, assim como os demais serviços oferecidos em uma grande cidade. Desta forma, o valor pode variar até $100 \%$ entre uma sauna localizada num bairro da Zona Sul e outra no subúrbio carioca. Tal fato decorre de encontrarmos, nas saunas localizadas na Zona Sul, um ambiente mais requintado e com decoração sofisticada, que inclui iluminação indireta, plantas e cascatas artificiais. Com relação aos serviços oferecidos aos usuários, estes ambientes disponibilizam salas de vídeo, american bar, toalha, sabonete, xampu, entre outros itens.

Além das diferenças impostas pela localização e pelo público que as frequenta, existe outra característica que deve ser apreendida como ponto principal de distinção entre uma sauna de 'pegação' e uma de boys. Algumas saunas contratam e oferecem aos clientes o serviço dos prostitutos ${ }^{2}$, que normalmente são rapazes jovens (entre 18 e 30 anos), que oferecem programas sexuais para os clientes. Normalmente, as relações entre os profisssionais do sexo e os clientes são em parte tratadas e mediadas pelo empresário, proprietário ou gerente da casa. Este é responsável pela organização do estabelecimento e decide o valor a ser cobrado pelo programa sexual, além dos preços das suítes a serem pagos pelos clientes. Os boys, diretamente com o cliente, combinam o preço do programa para além do valor estipulado pela sauna, em função das negociações em relação às práticas sexuais acordadas anteriormente por exemplo, felação, com uso ou não de preservativo; relação envolvendo mais de um boy e cliente; dentre outras. Em função dos vínculos de convívio estabelecidos entre boys e clientes é possível acordar outros tipos de programas externos ao estabelecimento e em horários e dias alternativos, como frequentar a residência dos clientes, ir a um hotel/motel e fazer acompanhamento em viagens e festas.

Nesses recintos, o atendimento aos clientes fica restrito ao horário de funcionamento do local e às normas internas impostas pelo empresário/ proprietário/ gerente da casa, configurando assim uma territorialidade específica bastante diferente daquela encontrada nas áreas de prostituição dos logradouros públicos. Um micro território é então configurado, estando os clientes e rapazes de programa sujeitos às imposições passíveis de punição em caso de transgressão. Apesar de existirem diversos aspectos diferenciadores entre as saunas, como a variação dos preços e a qualidade dos serviços oferecidos, as regras e acordos estabelecidos são semelhantes entre proprietário/empresário-boy-cliente.

Outro fator que aproxima tais estabelecimentos, fazendo com que essa semelhança seja percebida logo de entrada, diz respeito aos serviços oferecidos no interior dos mesmos, tais como bares, suítes, boates, jogos, salas e dispositivos afins, bem como os utensílios de higiene e segurança utilizados nas relações propriamente ditas - preservativos, cremes, materiais para banhos.

Devemos salientar que outra fonte de arrecadação existente nas saunas consiste no aluguel das cabines, que variam de tamanho e preço e nas quais ocorrem efetivamente as relações sexuais entre boys e clientes. Cumpre mencionar que os contatos iniciais entre cliente e garotos de programa realizam-se nos espaços internos do estabelecimento, como as salas de banho, de recreação e lazer, além dos corredores e, muitas vezes, na boate e demais dependências.

Os códigos são bastante explícitos, ou seja, a prática de abordagem ao cliente, empreendida pelo garoto de programa, geralmente se dá pelos contatos íntimos, nos quais procuram seduzir o usuário para a consumação do ato sexual, que será realizado nas cabines. Entre os recursos de sedução, destacam-se as performances dos garotos de programa que circulam nas dependências, muitas vezes nus, exibindo seus atributos físicos de forma provocativa. Apesar dos diversos 'mecanismos de sedução', às vezes a aproximação dos boys e a manifestação de interesse do cliente não se concretizam, e o programa sexual pode não ser realizado. No tocante às estratégias de aproximação e abordagem entre prostitutos e clientes, tanto no aspecto da escolha do par como em relação ao preço extra a ser cobrado, percebeu-se que pequenos grupos parceiros atuam em conjunto nas investidas sobre os clientes no interior das saunas, exercendo uma 'disputa' por programas ou trabalhando em conjunto.

$\mathrm{O}$ estigma e o imaginário construído em torno do estabelecimento pelos clientes e boys, como também os atributos físicos do boy, influenciam decisivamente na mobilidade e/ou exclusividade do profissional do sexo. Em muitos casos, o boy associa a sauna em que trabalha como status ou depreciação de sua imagem, refletindo na possibilidade de ganhos; por isso, muitas vezes, frequenta apenas um único estabelecimento ou, então, private clubs consideradas entre eles do mesmo padrão de seu status. Ao mesmo tempo, a situação inversa também é evidenciada: boys que frequentam saunas consideradas de padrão inferior, quando 
comparadas àquelas de melhor infraestrutura física e de higiene, não frequentam outras que apresentam status diferente.

Com base nos resultados estatísticos informados pelo projeto: 'Babadão da Promoção da Saúde'3, cujos questionários foram aplicados entre outubro e novembro de 2007, podemos traçar um perfil social dos garotos de programa que trabalham nas saunas de relações homocomerciais. Em um universo de 127 questionários aplicados, mais de $55 \%$ dos rapazes têm idade entre 19 e 30 anos; no tocante à escolaridade, mais de $40 \%$ não apresenta efetivação do ensino médio completo, sendo que, deste total, $18 \%$ não possui o ensino fundamental. Quanto ao local de procedência dos boys, $42 \%$ tem sua origem em municípios do Estado do Rio de Janeiro, sendo que, deste total, 45\% é procedente da Baixada Fluminense, notadamente de Duque de Caxias e Nova Iguaçu. Outros municípios que merecem destaque e que compõe este universo são Niterói e São Gonçalo.

Ao analisarmos tais resultados, podemos concluir que o perfil dos rapazes de programa que frequentam as saunas com relações homocomerciais caracteriza-se pelo baixo nível de escolaridade, além de residirem em municípios que integram a região metropolitana do Rio de Janeiro e apresentam atualmente problemas relacionados a uma realidade socioeconômica precarizada (OLIVEIRA, 2004; SIMÕES, 2006). Grosso modo, de acordo com as entrevistas e conversas informais, muitos desses profissionais se inserem nas relações homocomerciais em função de seu baixo grau de escolaridade e, consequentemente, ausência de qualificação técnico-profissional, não sendo inseridos no mercado de trabalho formal ou complementando sua renda em atividades que possuem remuneração insuficiente para manutenção de suas necessidades cotidianas.

Nas saunas de relações homocomerciais, o risco da repressão policial é menor quando comparado com a prostituição manifestada nos logradouros públicos. A repressão que o Estado exerce sobre esses territórios, através da polícia, e as críticas que os moradores das respectivas áreas fazem costumam ser menores pela discrição dos estabelecimentos, que geralmente contam com mecanismos de proteção dos frequentadores e dos boys, não chamando atenção dos transeuntes, além de manter a privacidade do referido serviço. Podemos aferir que tal situação é praticamente inexistente, ao contrário da prostituição de rua, na qual os policiais atuam de forma repressiva em defesa da manutenção das práticas morais e de condutas impostas pela sociedade que achacam michês e clientes; em contrapartida, nos estabelecimentos fechados, esses agentes, de certa forma, os protegem e se relacionam pacificamente com seus proprietários e gerentes, recebendo, muitas vezes, 'propina' para permitir seu funcionamento.

Tais fixos sociais permaneceram com sua formaaparência original: são antigas residências ou hotéis que sofreram um processo de refuncionalização para transformarem-se em saunas e private clubs específicos, nesse caso, de relações homocomerciais.

A partir de matéria publicada no jornal 'O Globo' (2001), com nomes fictícios, as casas de prostituição na cidade do Rio de Janeiro conseguiram registros em cartórios na Junta Comercial e licenciamento da prefeitura sob a fachada de prestação de serviços legais. Para escapar de processo criminal, segundo a legislação brasileira, os proprietários de alguns estabelecimentos de prostituição burlam a fiscalização, mudando a razão social em alterações contratuais que camuflam o verdadeiro ofício. Este exemplo, quanto à prostituição feminina, pode ser transposto para o nosso objeto de estudo, pois os estabelecimentos de prostituição masculina não poderiam entrar em funcionamento por ser uma atividade ilegal. Empresários encontram mecanismos para escapar às normas, códigos e leis municipais e estaduais, e assim manter esses estabelecimentos em funcionamento. $\mathrm{O}$ funcionamento também passa pelos 'acertos' periódicos que são feitos com os agentes repressores do Estado (policiais), em que o suborno propicia uma relação de conivência e parcialidade.

Quanto à distribuição espacial das mesmas, há uma localização em áreas específicas da cidade. Na realidade, em 2007, foi registrado um total de nove saunas, sendo duas no bairro da Glória (Club 177 e Sauna Spazio 18), uma na praça da Bandeira (Sauna SPA 73), três em Copacabana (Point 202, Estação e Roger's Termas), duas na Área Central (Club Meio Mundo - FIGURA 1 - e Caracalla) e uma no bairro de Cascadura (Club 89).

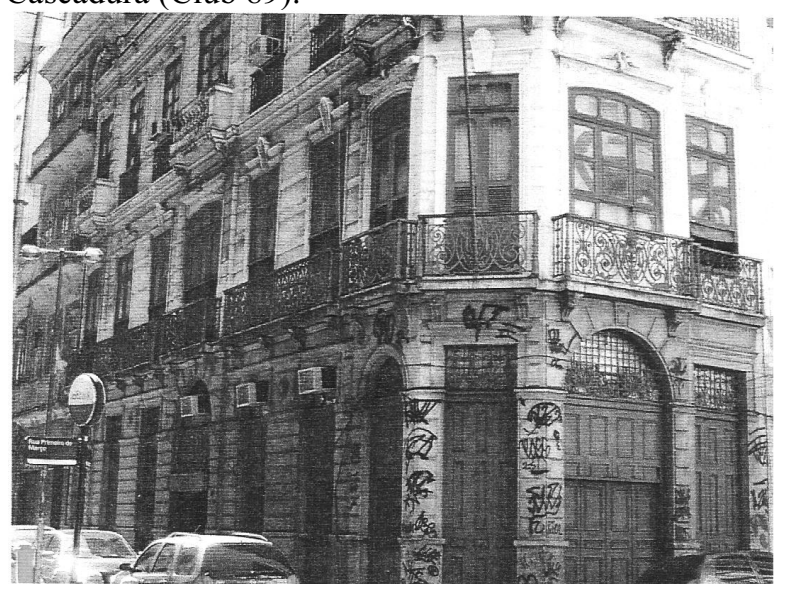

FIGURA 1: Sauna Meio Mundo, localizada na rua Teófilo Otoni, 18 na Área Central.

Fotografado por Gessé da Silva Maia, 2007. 
Em recente pesquisa realizada para confirmação da localização dos referidos estabelecimentos através de sites especializados e contatos telefônicos, deparamonos com uma diminuição desse quantitativo, reduzido para cinco, conforme indicado no quadro abaixo:

QUADRO 1 - Saunas e Private Clubs de Boys, 2011

\begin{tabular}{c|c|}
\hline Nome & Bairro \\
\hline Club 117 & Glória \\
\hline Club 89 & Cascadura \\
\hline Club Meio Mundo & Centro \\
\hline Point 202 & Copacabana \\
\hline Sauna Spazio 18 & Glória \\
\hline
\end{tabular}

Fonte: Pesquisa de Campo e análise em sites especializados entre os anos de 2005 e 2011.

Entre os principais motivos que explicam a diminuição do número deste tipo de estabelecimento, o primeiro refere-se à concorrência das saunas, principalmente o Club 117 (FIGURA 2), que é considerado, para os padrões nacional e carioca, um dos melhores nesse ramo. Outro aspecto relevante é sua localização, próxima à Área Central e de fácil acessibilidade em decorrência de sua proximidade com uma das estações do metrô (Glória), além de várias opções de transportes urbanos.

FIGURA 2: Sauna Club 117, localizada na rua Cândido Mendes no bairro da Glória.

Fotografado por Gessé da Silva Maia, 2007.
Quanto ao término das atividades da sauna Caracalla (FIGURA 3), situada na rua Mem de Sá, o fato pode ser entendido, e foi mencionado pelos clientes, como decorrente de sua localização na periferia imediata da Área Central, que, segundo relatos dos entrevistados, é considerada 'perigosa'; além da concorrência com as demais, que contribuíram para fortalecer um imaginário negativo e (pré) conceitos atrelados à periculosidade e violência existentes em relação ao seu entorno.

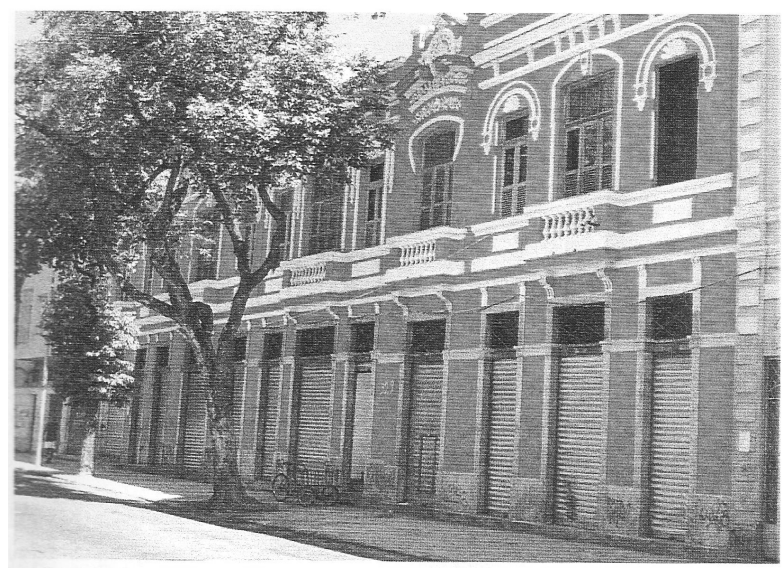

FIGURA 3: Sauna Caracalla, localizada na rua Mem de Sá na Área Central.

Fotografado por Gessé da Silva Maia, 2007.

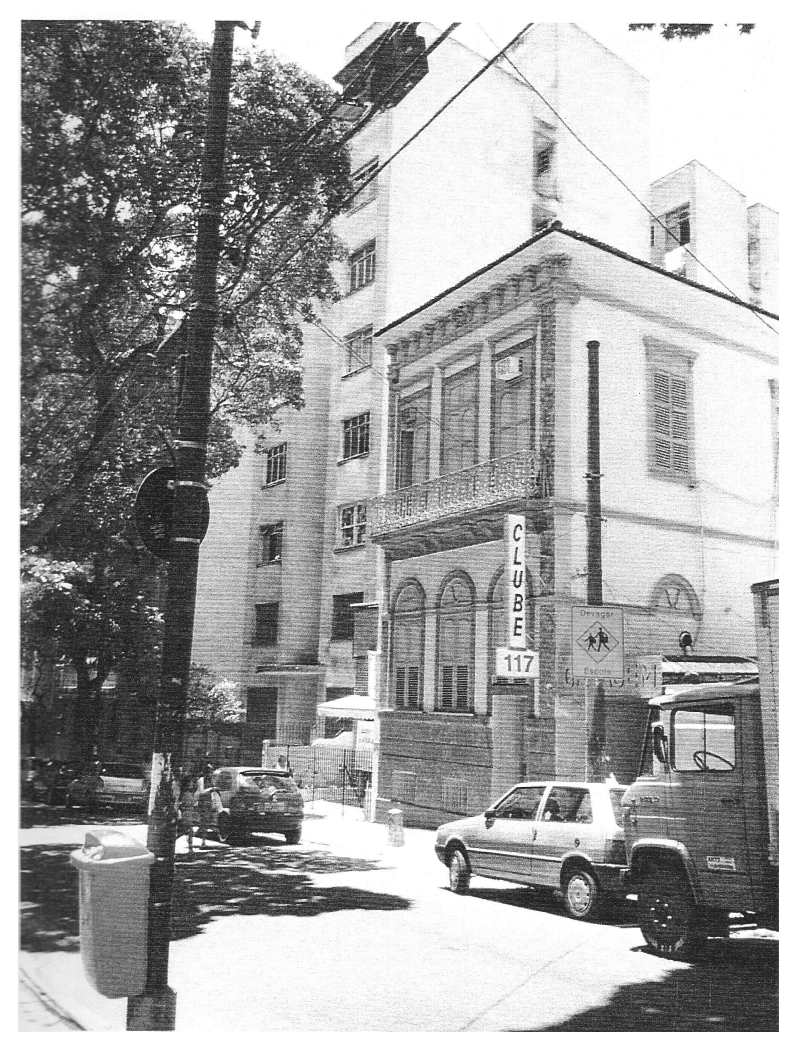

Em decorrência da importância do Club 117 (FIGURAS 4 e 5), na cidade do Rio de Janeiro, e sua repercussão internacional no universo gay, faz-se pertinente analisar o seu espaço interno. Esse estabelecimento encontra-se estruturado em três andares: i) o primeiro (segundo andar), situado no mesmo nível da rua Cândido Mendes, é constituído por um hall de entrada; uma recepção na qual os atendentes cadastram $\mathrm{o}$ cliente, distribuem chaves dos armários para guardar roupas e pertences dos usuários e boys e onde também é solicitado o pedido de suítes para as práticas sexuais, além do acerto final dos serviços utilizados pelos clientes e boys; um corredor de 
passagem para banheiro e salas de televisão, boate e bar, além de um lounge externo para fumantes e descanso; ii) o subsolo (considerado o primeiro andar), onde se encontram a sala com armários dos clientes, um corredor com armários dos boys; banheiros, sala de massagem, chuveiros e as saunas seca e a vapor; um corredor de passagem que liga uma sala de entretenimento ao bar; e suítes; iii) no terceiro andar está localizada a maioria das suítes de melhor padrão. Nesses ambientes internos transitam empregados, clientes e boys, estabelecendo as relações de contato, conforme já analisado.

A importância/relevância dessas saunas dentro do universo gay extrapola a sua dinâmica e rotina, chegando a assumir postura e militância junto ao movimento GLBT (Gays, Lésbicas, Bissexuais, Travestis e Transexuais), patrocinando eventos e ao mesmo tempo promovendo suas atividades em paradas gays, passeatas e concursos de beleza gay.

\section{Considerações finais}

Entendemos que a
Geografia tem como
compromisso refletir, entender
e procurar explicar os
fenomenos sociais que permeiam o nosso cotidiano. A prostituição, e aqui tratando da masculina no interior das saunas e private clubs, merece ser alvo de estudos por parte dos geógrafos, pois se trata de um fenômeno causador de embates sociais, presente no contexto dos centros urbanos.

A cidade do Rio de Janeiro

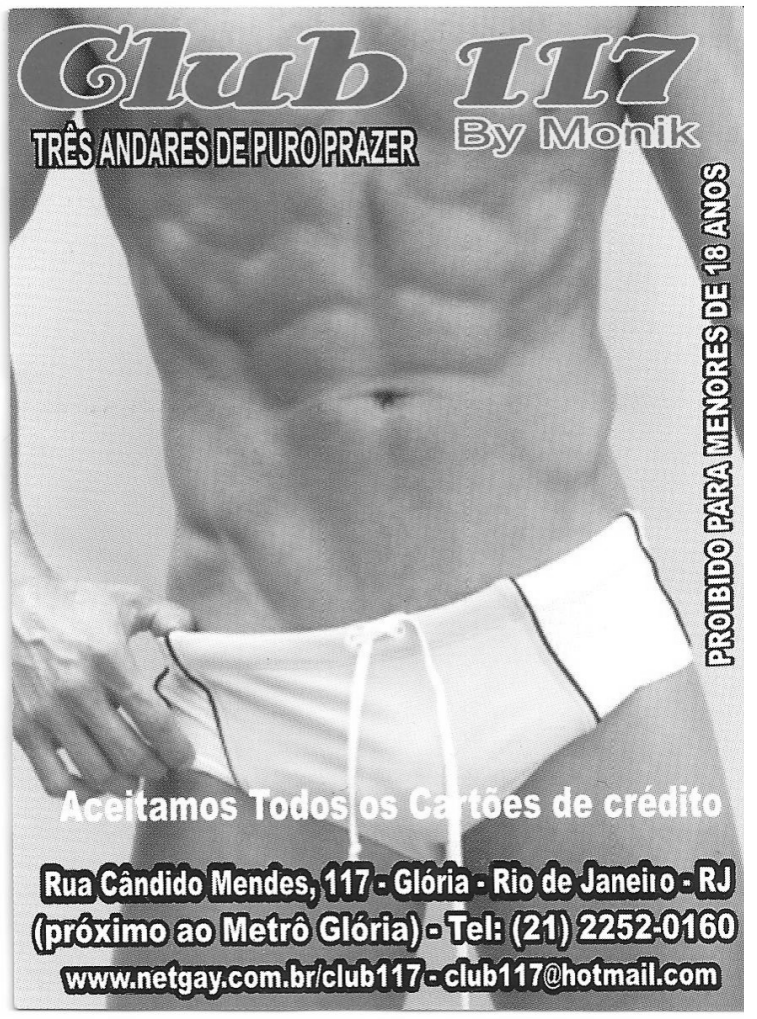

FIGURA 4: Panfleto coletado durante pesquisa de campo, agosto de 2010 .
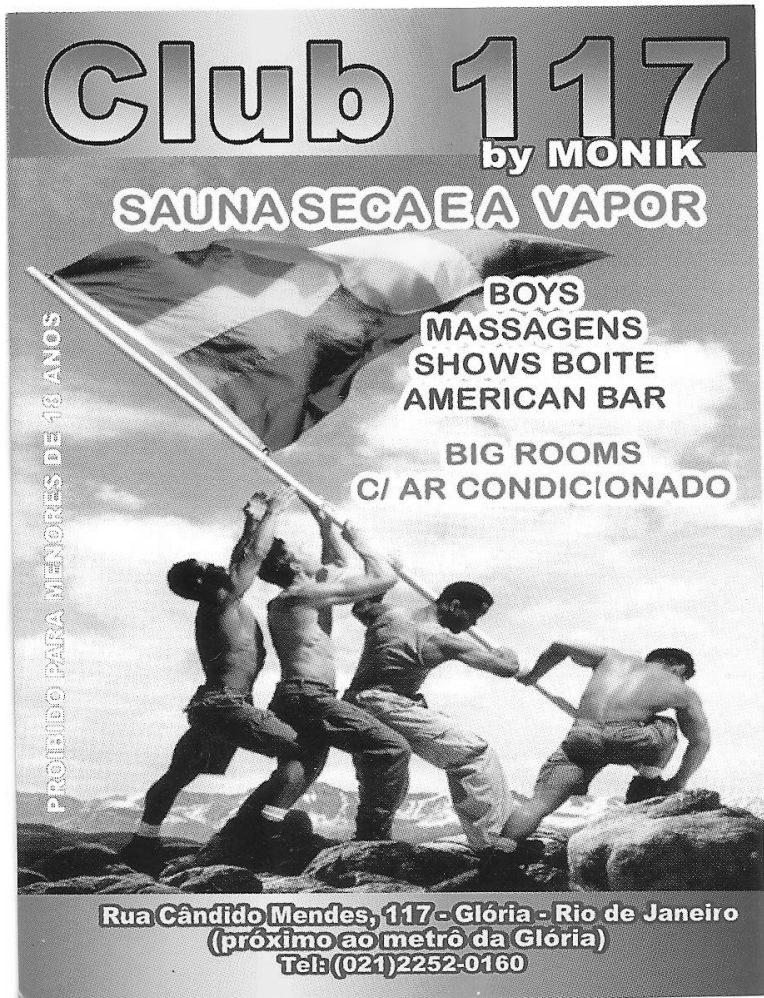

FIGURA 5: Panfleto coletado durante pesquisa de campo, agosto de 2010 . desponta, ainda no século XIX, como cenário da gênese da prostituição masculina e que apresenta, nos dias atuais, mudanças consideráveis em relação a essa atividade. Alguns empresários perceberam que agregar os serviços oferecidos pelos boys à segurança e à privacidade que esses estabelecimentos oferecem poderia atrair uma gama maior de clientes; eles são, sem dúvida, importantes agentes na manutenção e crescimento do fenômeno das saunas nesta cidade. Entendemos, portanto, que tanto a prostituição masculina e os profissionais do sexo receberam novas denominações ao longo do tempo (bagaxas, pederastas, michês, garotos de programa e boys), como, também, a sua função no cerne do espaço urbano continua em constante mutação.

Tanto no passado quanto nos dias atuais, essa atividade continua a ser tolerada, mas não aceita. A necessidade dos serviços desses profissionais é latente para a manutenção das relações sociais na metrópole carioca. Notadamente, o enfoque moral ou 'moralista e moralizante' já não está mais no centro das discussões e reflexões como esteve no passado. Atualmente, a atenção voltada para as relações homocomerciais está mais relacionada com questões de saúde e a sobrevivência dos boys e clientes, ainda que não revestidas da legalidade profissional.

A mútua construção simbólica de proteção/segregação lembra as discussões sobre a região moral, que se refere ao contexto e à frequência de

Miguel Angelo Ribeiro, Rafael da Silva Oliveira e Gessé da Silva Maia 
certas populações em se agruparem em áreas específicas do espaço urbano, sua mobilidade (trânsito) à procura de sexo, diversão, prazeres e 'outros vícios próximos à ilegalidade’ (PERLONGHER, 1988).

Tal compreensão abrange uma gama diversificada de espaços urbanos onde se constituem redes de relações sociais, que implicam modos de vida, linguagens, sinalizações e trocas entre sujeitos com vivências homocomerciais.

A prostituição masculina demarca seu território, e esta demarcação é seguida de territorialidades específicas de acordo com cada segmento dos profissionais do sexo.

Desta forma, tais profissionais impõem suas territorialidades, delimitando seus territórios com gestos, códigos e práticas, nos quais os rapazes de programa (michês) que trabalham nos espaços abertos utilizam seus atrativos corporais para territorializar e ao mesmo tempo atrair seus clientes. Por sinal, convém mencionar que este segmento da prostituição masculina sofreu um processo de retração de seus territórios nos espaços públicos do Rio de Janeiro, ao passo que a prostituição nos ambientes fechados é acompanhada de formas distintas de territorialidades, além de guardar algumas especificidades instituídas pelos proprietários dos estabelecimentos onde as relações são estabelecidas entre boys e clientes.

Outro aspecto importante diz respeito à sua localização, que acompanha uma dinâmica relacionada ao status e valoração dos bairros, a partir do valor dos imóveis e pela procura dos serviços oferecidos pelos profissionais do sexo. Ainda nesse sentido, as saunas são, em alguns casos, agentes capazes de refuncionalizar espaços antes desprovidos de atividades. Foi também possível constatar que antigos imóveis, que antes funcionavam como hotéis ou residências, passaram por mudança de conteúdo e foram transformados externa e internamente, em ambientes adaptados, para a prática da atividade em tela, mudando sua função, mas mantendo em sua grande maioria as características da estrutura original.

Por fim, podemos afirmar que a prostituição masculina fechada, as saunas e private clubs de boys configuram verdadeiros micro territórios, com suas territorialidades, imprimindo nos espaços urbanos feições que as identificam e que demarcam uma centralidade destes fixos sociais, exercendo papel importante na sua organização e provocando uma interação entre clientes e rapazes de programa, ratificando assim o papel da geografia, em que a mesma se realiza através de suas diferenciações espaciais e de seus movimentos.
Segundo Costa (2010, p.18), "pegação é uma gíria comum da cultura gay brasileira. Significa paquerar e promover atos sexuais em lugares inusitados ou lugares específicos para isso. Ocorre na formação do mercado gay nas grandes cidades, casas fechadas destinadas à pegação ou que oportunizam determinados atos. Estes ambientes reproduzem formas de 'cantos' e labirintos escuros por onde os sujeitos transitam e promovem atos sexuais".

2 Os boys que frequentam um determinado private club (sauna) possuem apenas uma relação contratual verbal, ou seja, não existe vínculo empregatício formalizado entre as partes, tendo somente que registrar a carteira de identidade no estabelecimento, pagar na entrada a taxa relativa ao uso do armário e de sua permanência a partir do horário estabelecido de trabalho com o proprietário/gerente.

3 Segundo site do projeto, este foi "idealizado a partir das experiências de jovens frequentadores do Grupo pela Vida-RJ, buscando-se conhecer e avaliar melhor as práticas de prevenção, educação e promoção da saúde em relação às DST e AIDS. O estudo foi orientado a partir do aumento de dados epidemiológicos (novos casos) de DST e AIDS, principalmente, infecção por HIV, envolvendo jovens (16 a 30 anos). A proposta objetivou um levantamento socioeducativo em saunas gays junto a jovens envolvendo o seu conhecimento acerca de práticas de prevenção e educação utilizados nas suas relações homoeróticas e homocomerciais (os mesmos que atuam como profissionais do sexo). O projeto firmou parceria com saunas gays onde há frequência de garotos de programa e drags-queens que se apresentam em shows, além de bares, boates, raves e quiosques, todos com práticas homocomerciais, com vistas à formação de agentes mobilizadores" (extraído de <www.pelavidda.org.br/babadao.html>, acessado em fevereiro de 2011).

\section{Referências}

CAMPOS, Heleniza Ávila. "Permanências e mudanças no quadro de requalificação de cidades brasileiras: o caso das territorialidades do sexo na Área Central de Recife". Revista Território, Rio de Janeiro, ano V, n. 9, p. 25-43, jul./dez., 2000. 
COSTA, Benhur Pinós da. Espaço urbano, cotidiano, cultura e espaços de proximidade: o caso das micro territorializações de sujeitos orientados para o mesmo sexo. 2010, (mimeo).

MAIA, Gessé da Silva. Os territórios fechados da prostituição masculina na cidade do Rio de Janeiro: o exemplo das saunas. 2008. Monografia de PósGraduação (Lato Sensu em Políticas Territoriais no Estado do Rio de Janeiro pela Universidade do Estado do Rio de Janeiro) - Programa de Pós-Graduação em Geografia, UERJ, Rio de Janeiro - RJ.

O GLOBO: Rio. 22.04.2001, p.17

OLIVEIRA, Rafael da Silva "Distintas noções de Baixada Fluminense: a busca do entendimento da constituição política da região - apresentação otimista sobre o seu crescimento latente". In: OLIVEIRA, Rafael da Silva (Org.). Baixada Fluminense: novos estudos e desafios. Rio de Janeiro: Paradigma, 2004. p.17-47.

MATTOS, Rogério Botelho de \& RIBEIRO, Miguel Angelo Campos. "Territórios da prostituição nos espaços públicos da área central do Rio de Janeiro". In: Boletim Goiano, v. 15, n. 1: p. 57-79, jan./dez., 1995.

MATTOS, Rogério Botelho. "A dinâmica dos espaços da prostituição na cidade do Rio de Janeiro: 18401940”. RIBEIRO, Miguel Angelo (Org.). Território e Prostituição na metrópole carioca. São João de Meriti/RJ: Ecomuseu Fluminense, 2002. p.57-87.

PERLONGHER, Néstor O. O negócio do michê - a prostituição viril em São Paulo. São Paulo: Brasiliense, 1987.

RAFFESTIN, Claude. Por uma geografia do poder. São Paulo: Ed. Ática, 1993.

RIBEIRO, Miguel Angelo. "Prostituição de rua e turismo: a procura do prazer na cidade do Rio de Janeiro". In: RODRIGUES, Adyr Apparecida Balastreri (Org.). Turismo. Modernidade. Globalização. São Paulo: HUCITEC, 1997.

SACK, Robert D. Human territoriality - It's theory and history. Cambridge: Cambridge University Press, 1986.

SIMÕES, Manoel Ricardo. A cidade estilhaçada: reestruturação econômica e emancipações municipais na Baixada Fluminense. 2006. Tese
(Doutorado em Geografia) Universidade Federal Fluminense. Niterói: UFF.

SOJA, Edward W. Geografias pós-modernas: a reafirmação do espaço na teoria social crítica. Rio de Janeiro: Jorge Zahar, 1993.

SOUZA, Marcelo José Lopes de. "O território: sobre espaço e poder autonomia e desenvolvimento". In: CASTRO, Iná Elias; GOMES, Paulo César da Costa; e CORRÊA, Roberto Lobato (Org.). Geografia: conceitos e temas. Rio de Janeiro: Bertrand Brasil, 1995. p. $77-116$

TUAN, Yi-Fu. Topofilia. São Paulo: Difel, 1980.

Site consultado:

$<$ www.pelavidda.org.br/babadao.html $>$. Acesso em 8 de julho de 2011. 